\title{
Soma térmica de subperíodos do desenvolvimento da planta de melancia
}

\author{
Thermal time of developmental phases in watermelon
}

\author{
Roberto Trentin ${ }^{\mathrm{I}}$ Fábio Schreiber ${ }^{\mathrm{I}}$ Nereu Augusto Streck ${ }^{\mathrm{II}}$ Galileo Adeli Buriol ${ }^{\mathrm{II}}$
}

\section{RESUMO}

A temperatura do ar é um dos elementos meteorológicos mais importantes que afetam o desenvolvimento da planta de melancia. Para representar o efeito da temperatura do ar sobre o desenvolvimento das plantas, temse usado o método da soma térmica, por ser um método simples e por ser uma melhor medida de tempo biológico que dias do calendário civil ou dias após a semeadura. O objetivo deste trabalho foi determinar a soma térmica de três subperíodos de desenvolvimento da planta de melancia por diferentes métodos de cálculo. Um experimento em campo foi conduzido em Santa Maria, RS, com duas datas de semeadura durante o ano agrícola 2006-2007 (05/09/2006 e 21/09/2006). Usou-se a cultivar "Crimson Sweet" no delineamento experimental de blocos ao acaso com seis repetições. Os subperíodos foram semeadura-emergência (SE-EM), emergência-florescimento (EM-FL) e florescimento-colheita (FL-CO). A soma térmica diária (STd, ${ }^{\circ} \mathrm{C}$ dia) foi calculada por três métodos considerando-se as temperaturas cardinais de $10^{\circ} \mathrm{C}, 33^{\circ} \mathrm{Ce}$ $42^{\circ} \mathrm{C}$. A soma térmica acumulada $\left(\mathrm{STa},{ }^{\circ} \mathrm{C}\right.$ dia) para os três subperíodos foi calculada somando-se os valores de STd. Não se constatou diferença na duração (STa) do ciclo total e dos subperíodos entre os três métodos de soma térmica utilizados. A duração (STa) do subperíodo EM-FL foi similar nas duas datas de semeadura $\left(417^{\circ} \mathrm{C}\right.$ dia), mas a STa dos subperíodos SE-EM e FL-CO variou de 98 a $130^{\circ} \mathrm{C}$ e de 770 a $840^{\circ} \mathrm{C}$ dia, respectivamente.

Palavras-chave: Citrullus lanatus, tempo térmico, graus-dia, temperaturas cardinais.

\section{ABSTRACT}

Air temperature is one of the most important environmental factors that drive development in watermelon.
Thermal time is usually used for representing the effect of the air temperature on plant development because it is a simple method and a better time descriptor than calendar days or days after sowing. The objective of this study was to calculate the thermal time of three developmental phases in watermelon using different methods. A field experiment was carried out in Santa Maria, RS, Brazil, with two sowing dates during the 2006-2007 growing seasons (09/05/2006 and 09/21/2006). The cultivar 'Crimson Sweet' was used and the experimental design was a complete randomized block with six replications. Developmental phases were sowing-emergence (SO-EM), emergence-flowering (EM-FL) and flowering-harvest (FL-HA). Daily degree-days $\left(D D D,{ }^{\circ} \mathrm{C}\right.$ day) were calculated with three methods using the cardinal temperatures of $10^{\circ} \mathrm{C}, 33^{\circ} \mathrm{C}$ and $42^{\circ} \mathrm{C}$. Thermal time (TT, ${ }^{\circ} \mathrm{C}$ day) during the three developmental phases was calculated by accumulating DDD. There was no difference in the duration, in TT, for the total cycle and the developmental phases among the three methods of thermal time used. The duration (in TT) of the EM-FL phase was similar $\left(417^{\circ} \mathrm{C}\right.$ day) in the two sowing dates, but the TT of the SO-EM and $\mathrm{FL}$-HA phases varied with sowing date from 98 to $130^{\circ} \mathrm{C}$ day and from 770 to $840^{\circ} \mathrm{C}$ day, respectively.

Key words: Citrullus lanatus, thermal time, degree-days, cardinal temperatures.

\section{INTRODUÇÃO}

A melancia (Citrullus lanatus (Thumb). Mansf) família Cucurbitaceae, originária do continente africano, é uma fruta bastante apreciada e de grande importância econômica em diferentes partes do mundo, principalmente em regiões tropicais e subtropicais. Suas

ICurso de Agronomia, Centro de Ciências Rurais (CCR), Universidade Federal de Santa Maria (UFSM), Santa Maria, RS, Brasil.

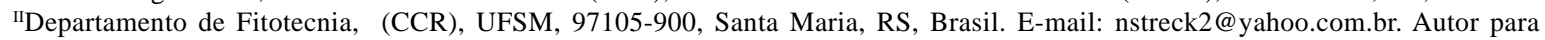
correspondência.

IIIDepartamento de Fitotecnia, CCR, UFSM. Centro Universitário Franciscano (UNIFRA), Santa Maria, RS, Brasil. 
propriedades refrescantes e diuréticas, associadas ao sabor agradável e ao baixo teor calórico, fazem da fruta uma excelente alternativa para os adeptos dos mais variados regimes alimentares. Ela é a segunda fruta mais produzida no mundo, sendo o Brasil o décimo produtor mundial e o Rio Grande do Sul o maior produtor, respondendo por $28,5 \%$ da produção brasileira ou 555.135 toneladas (IBGE, 2008).

Um dos elementos meteorológicos mais importantes que afetam o desenvolvimento da melancia é a temperatura do ar. A quantificação do efeito da temperatura do ar sobre as plantas, geralmente, é realizada utilizando o método da soma térmica ou de graus-dia (GILMORE \& ROGERS, 1958; ARNOLD, 1960; JEFFERIES \& MACKERRON, 1987), sendo uma melhor medida de tempo biológico que dias do calendário civil ou dias após a semeadura (GILMORE \& ROGERS, 1958).

O método de graus-dia baseia-se na premissa de que as plantas, para completarem cada subperíodo do desenvolvimento, necessitam de um somatório térmico, isto é quantidade de energia acumulada acima da temperatura-base favorável ao desenvolvimento vegetal abaixo da qual os processos metabólicos paralisam ou ocorrem a uma taxa tão pequena que podem ser desprezados. Pressupõe ainda uma relação linear entre acréscimo de temperatura e desenvolvimento vegetal (BRUNINI et al., 1976).

Modelos de estimativa da data de ocorrência dos principais estádios de desenvolvimento da planta de melancia são importantes por auxiliarem a implantação da cultura e as práticas de manejo, tais como semeadura em datas que proporcionem a coincidência dos períodos críticos da cultura com aqueles em que as restrições são menores, aplicação da adubação e produtos fitossanitários. Assim, a soma térmica é um parâmetro de extrema relevância para a redução de riscos climáticos, uma vez que o conhecimento das exigências térmicas de uma cultura contribui para a previsão da duração do ciclo da planta (BARBANO et al., 2001).

Diversos autores utilizaram a soma de grausdia para relacionar o desenvolvimento das plantas com a temperatura ambiente (ALVES et al., 2000; WUTKE et al., 2000; PAULA et al., 2005), porém, são escassos os estudos para a cultura da melancia, nas condições brasileiras. Apesar de ser bastante utilizada, deve-se mencionar que o conceito da soma térmica recebe algumas críticas (XUE et al., 2004). Entre elas está o fato de que existem vários métodos de cálculo (SANGOI \& SILVA, 1986; STRECK et al., 2005), o que pode ser uma limitação para comparar os graus-dia das fases de desenvolvimento das cultivares em diferentes trabalhos. Algumas vezes também os relatos nos trabalhos não são claros quanto ao método de cálculo utilizado (McMASTER \& WILHELM, 1997).

O ciclo de desenvolvimento da planta de melancia pode ser dividido em três subperíodos: semeadura-emergência (SE-EM), emergênciaflorescimento (EM-FL) e florescimento-colheita (FLCO). No subperíodo SE-EM, ocorre a germinação e, posteriormente, a emergência dos cotilédones. O subperíodo EM-FL se caracteriza pelo estabelecimento do sistema radicular, aumento da área folhar e fotossíntese. No subperíodo FL-CO, os produtos da fotossíntese são usados para o crescimento dos frutos.

O objetivo deste trabalho foi determinar a soma térmica dos três subperíodos de desenvolvimento da cultura de melancia por diferentes métodos de cálculo.

\section{MATERIAL E MÉTODOS}

Um experimento em campo foi conduzido no Campo Experimental do Departamento de Fitotecnia da Universidade Federal de Santa Maria (Latitude: 2943'S, longitude: 5342’W e altitude: $95 \mathrm{~m}$ ) durante o ano agrícola 2006-2007. A cultivar de melancia utilizada foi a Crimson Sweet, bastante utilizada pelos agricultores da região de Santa Maria e no restante do Rio Grande do Sul, com duas datas de semeadura: 05/ 09/2006 (Semeadura 1) e 21/09/2006 (Semeadura 2). O clima da região, segundo a classificação de Köppen, é Cfa Subtropical úmido, sem estação seca definida com verões quentes (MORENO, 1961). O solo representativo do local é um Argissolo Vermelho Distrófico arênico (EMBRAPA, 2006).

A semeadura foi realizada diretamente no solo em covas no espaçamento de $1 \mathrm{~m}$ entre fileiras e 1,25m entre plantas. Foram colocadas três sementes por cova. Quando surgia nas plântulas a primeira folha verdadeira, era feito o desbaste, deixando-se somente uma plântula por cova. A adubação foi feita nas covas com a formulação 8-18-20 de NPK, correspondendo a doses de $72 \mathrm{~kg} \mathrm{ha}^{-1}$ de N, 162kg ha-1 de $\mathrm{P}_{2} \mathrm{O}_{5}$ e $180 \mathrm{~kg} \mathrm{ha}^{-1}$ de $\mathrm{K}_{2} \mathrm{O}$. As plantas foram irrigadas diariamente com mangueiras plásticas que permitiam o gotejamento de água visando manter o solo, empiricamente, próximo da capacidade de campo para ter as plantas crescendo e desenvolvendo-se sem deficiência hídrica no solo. A cultura foi mantida livre de plantas daninhas por meio de capinas manuais e foram realizados os tratos fitossanitários recomendados para a cultura.

A unidade experimental (repetição) constituiu-se de uma fileira de $10 \mathrm{~m}$ de comprimento (sete plantas por fileira), com as duas fileiras laterais 
como bordadura. O delineamento experimental foi blocos ao acaso com seis repetições e duas datas de semeadura.

As datas de emergência (EM) e florescimento (FL) foram consideradas aquelas do dia em que $50 \%$ das plantas do conjunto de plantas do experimento atingiram estes estádios de desenvolvimento. A data do ponto de colheita (CO) ocorreu quando foram observadas mudanças de coloração, de verde opaco para verde brilhante na casca de $50 \%$ dos frutos do conjunto de plantas do experimento.

Os dados de temperatura mínima e máxima diária do ar durante o período experimental foram coletados em uma estação meteorológica convencional pertencente ao 8o Distrito de Meteorologia (8o DISME), pertencente ao Instituto Nacional de Meteorologia (INMET), localizada, aproximadamente, a 100m da área experimental. Foi também medida a temperatura do solo, diariamente, a $2 \mathrm{~cm}$ de profundidade em uma cova de cada época de semeadura, às $9 \mathrm{~h}$ e às $15 \mathrm{~h}$.

A soma térmica diária (STd, ${ }^{\circ} \mathrm{C}$ dia) foi calculada por três métodos (GILMORE \& ROGERS, 1958; ARNOLD, 1960):

Método 1: STd=(Tmed-Tb). 1 dia, se Tmed $<$ Tb então Tmed=Tb

Método 2: STd=(Tmed-Tb). 1 dia, se Tmed<Tb então
Tmed=Tb e se Tmed $>$ Tot então Tmed $=$ Tot Método3: STd=(Tmed-Tb). 1 dia quando $\mathrm{Tb}<\mathrm{Tmed}$ $\leq$ Tot e $\mathrm{STd}=($ Tot-Tb). $($ Tmax - Tmed $) /($ Tmax - Tot $)$ quando Tot $<$ Tmed $\leq$ Tmax

Em que: Tb é a temperatura base, Tot é a temperatura ótima e Tmax é a temperatura máxima para o desenvolvimento da planta de melancia e Tmed é a temperatura média diária do ar calculada pela média aritmética entre as temperaturas mínima e máxima diária do ar. A temperatura base foi de $10^{\circ} \mathrm{C}$ (BAKER \& REDDY, 2001) e as temperaturas ótima e máxima foram de $33^{\circ} \mathrm{C} \mathrm{e}$ $42^{\circ} \mathrm{C}$, respectivamente(SEDGLEY \& BUTTROSE, 1978; LORENZ \& MAYNARD, 1988). Arepresentação gráfica dos três métodos de cálculo da STd com as respectivas temperaturas cardinais é apresentada na figura 1. A soma térmica acumulada ( $\mathrm{STa},{ }^{\circ} \mathrm{C}$ dia) nos três subperíodos (SE-EM, EM-FL e FL-CO) foi calculada somando-se os valores de STd.

\section{RESULTADOS E DISCUSSÃO}

As temperaturas médias diárias do ar registradas durante o período experimental foram de $21,5^{\circ} \mathrm{C} \mathrm{e} 22,7^{\circ} \mathrm{C}$, respectivamente, para as semeaduras em 5 de setembro e 21 de setembro (Figura 2). Em ambas as semeaduras, as temperaturas máximas atingiram $37,5^{\circ} \mathrm{C}$. Os valores absolutos de temperatura

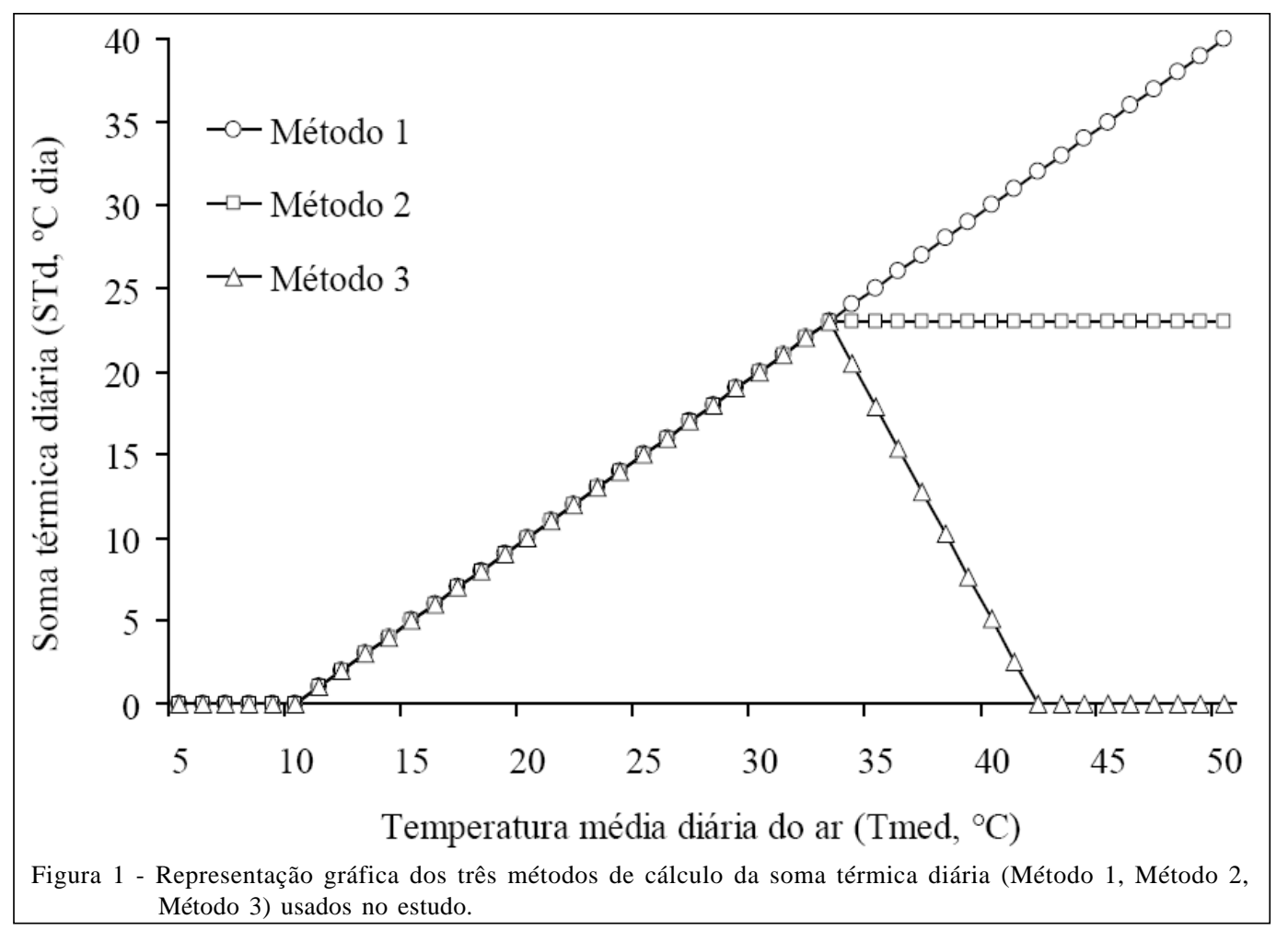

Ciência Rural, v.38, n.9, dez, 2008. 


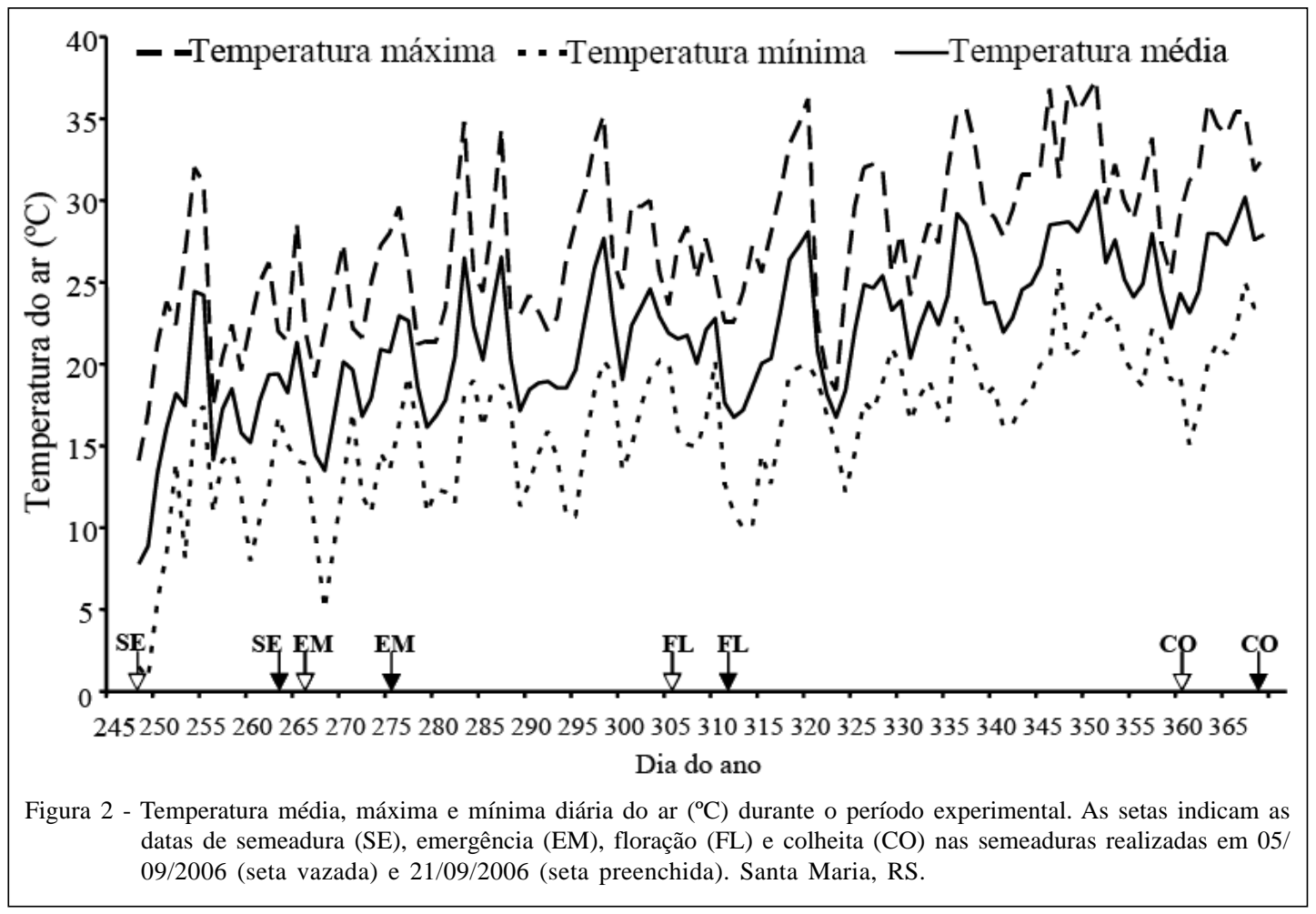

mínima foram de $0,8^{\circ} \mathrm{C}$ para a semeadura 1 e $5^{\circ} \mathrm{C}$ para a semeadura 2 . As temperaturas foram menores no início do experimento e no decorrer do experimento a temperatura foi aumentando gradativamente devido ao aumento do comprimento do dia e da perpendicularidade dos raios solares incidentes, em função da proximidade do solstício de verão no hemisfério sul.

A duração total do ciclo de desenvolvimento e dos subperíodos SE-EM, EM-FL e FL-CO variou entre as datas de semeadura quando o tempo foi contabilizado como dias do calendário civil, sendo maior na semeadura 1 (Figura 3a). Quando o tempo foi representado em soma térmica, a duração (STa, ${ }^{\circ} \mathrm{C}$ dia) do ciclo total e dos subperíodos foi igual nas duas épocas de semeadura nos três métodos, devido a temperatura média do ar durante todo o ciclo não ter sido superior à temperatura ótima de desenvolvimento para a cultura da melancia e a soma de ${ }^{\circ} \mathrm{C}$ dia do ciclo total ter sido menor na semeadura $1\left(1319^{\circ} \mathrm{C}\right.$ dia) (Figura 3b). A menor duração do ciclo total na semeadura 1 ocorreu porque a soma de ${ }^{\circ} \mathrm{C}$ dia do subperíodo FL-CO foi bastante reduzida nesta semeadura, apesar de uma maior duração do subperíodo SE-EM nesta época.

Na semeadura 2, a duração do subperíodo SE-EM foi menor, tanto em soma térmica $\left(98,4^{\circ} \mathrm{C}\right.$ dia $)$ quanto em dias do calendário civil (12 dias) comparado com $130,8^{\circ} \mathrm{C}$ dia ou 18 dias da semeadura 1 . Nesse subperíodo a semente e o ápice meristemático estão no interior do solo e, portanto, o elemento meteorológico que governa o desenvolvimento é a temperatura do solo. Assim, uma possível explicação para a maior duração, em soma de ${ }^{\circ} \mathrm{C}$ dia, do subperíodo SE-EM na semeadura mais cedo é que a temperatura do solo foi menor nesta época. As médias das temperaturas do solo a $2 \mathrm{~cm}$ de profundidade às 9 e $15 \mathrm{~h}$ da primeira data de semeadura para o subperíodo SEEM foram de $15,0^{\circ} \mathrm{C}$ e $22,6^{\circ} \mathrm{C}$, respectivamente, e a média da temperatura do ar foi de $18,2^{\circ} \mathrm{C}$. Já para a segunda data de semeadura foram $16,4^{\circ} \mathrm{C}$ às $9 \mathrm{~h}$ e $25,7^{\circ} \mathrm{C}$ às $15 \mathrm{~h}$ e a média da temperatura do ar foi de $19,7^{\circ} \mathrm{C}$. Com a menor temperatura do ar na semeadura 1 , a semente precisou de mais dias para completar suas necessidades térmicas e emergir nesta época. Outra suposição para explicar a diferença entre essas somas térmicas é que foram utilizadas temperaturas cardinais constantes para todo o ciclo de desenvolvimento. No entanto, tem sido demonstrado que as temperaturas cardinais não são constantes durante o ciclo de desenvolvimento vegetal (STRECK et al., 2003).

O subperíodo EM-FL foi mais longo na semeadura 1 , tanto em soma térmica $\left(417,3^{\circ} \mathrm{C}\right.$ dia) quanto em número de dias do calendário civil (40 dias). Entretanto, neste subperíodo, o valor da soma térmica entre as duas épocas de semeadura foi mais próximo, sendo que a diferença entre a semeadura 1 e a 


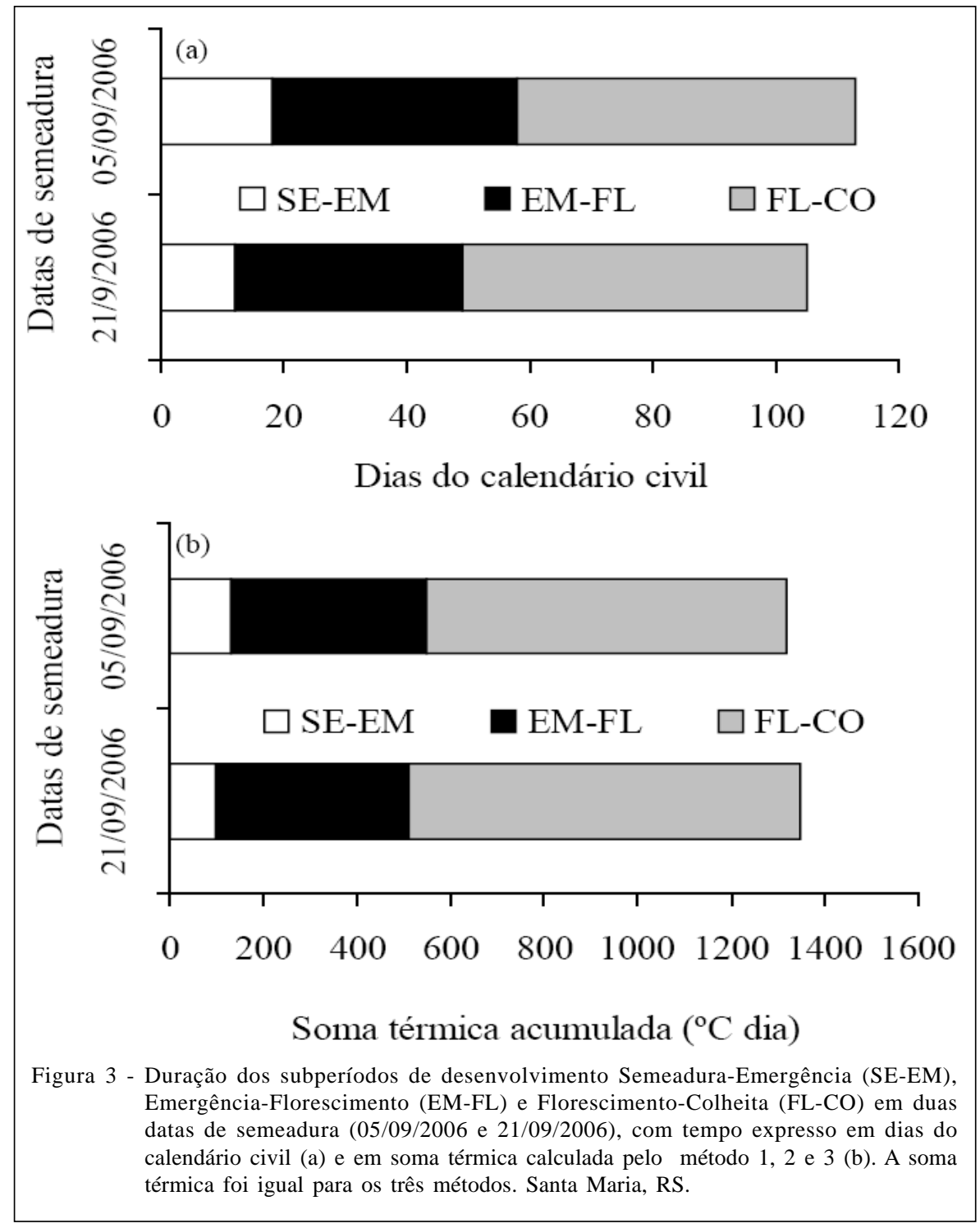

semeadura 2 foi de apenas $6,1^{\circ} \mathrm{C}$ dia, ou seja, na prática este valor é desprezível pois este acúmulo térmico ocorre em apenas um dia.

No subperíodo FL-CO, tanto em soma térmica $\left(770,9^{\circ} \mathrm{C}\right.$ dia) quanto em número de dias (55 dias) a duração foi menor para a semeadura 1 , sendo de $69,5^{\circ} \mathrm{C}$ dia inferior à segunda semeadura. Essa diferença pode ser devido à subjetividade do critério de determinação do ponto de colheita (CO), podendo ocorrer uma diferença entre um e dois dias, para mais ou para menos, na determinação da data de colheita da melancia. Outro fator que pode ter influenciado na diferença da soma térmica entre as datas de semeadura foi a temperatura máxima do ar que, na semeadura 2, chegou a valores superiores àqueles da temperatura ótima de desenvolvimento da melancia, $33^{\circ} \mathrm{C}$, podendo ter ocasionado estresse na planta e, assim, atrasado o seu desenvolvimento, pois temperaturas supra-ótimas diminuem a taxa de desenvolvimento vegetal (STRECK et al., 2003).

Tem sido demonstrado que a soma térmica para eventos do desenvolvimento vegetal pode variar com a época de semeadura em meloeiro, uma espécie similar à melancia em desenvolvimento (STRECK et al., 2005). Como possíveis causas da variação da soma térmica entre datas de semeadura estão a pressuposição de que a resposta de desenvolvimento da planta à temperatura é linear e sabe-se que a resposta de processos biológicos, inclusive desenvolvimento vegetal à temperatura, é não-linear (YIN et al., 1995; GRANIER \& TARDIEU, 1998; BONHOMME, 2000). Outra causa da variação da soma térmica entre épocas 
está relacionada à pressuposição de que a temperatura do ar é considerada como igual à temperatura da região de desenvolvimento da planta (ápice meristemático) ou no dossel vegetativo (McMASTER \& WILHELM, 1997), o que na prática nem sempre se verifica, dependendo da época do ano e do período do dia (GRANIER \& TARDIEU, 1998). Vale ressaltar também que o método da soma térmica deve ser bem descrito no trabalho. Por exemplo, McMASTER \& WILHELM (1997) demonstraram que o modo como a temperatura base é incorporada no cálculo (antes ou depois de calcular a temperatura média diária) pode causar uma diferença na predição da data de ocorrência da maturação fisiológica em trigo de até 14 dias.

Uma característica do método da soma térmica é a simplicidade do cálculo, motivo principal de sua difusão e uso no meio acadêmico entre extensionistas e pesquisadores, para representar o tempo biológico em plantas. No entanto, há relatos de frustrações com o uso deste método, não sendo sempre garantia de sucesso (PAULA et al., 2005).

\section{CONCLUSÃO}

Considerando-se as temperaturas cardinais de $10^{\circ} \mathrm{C}, 33^{\circ} \mathrm{C} \mathrm{e} 42^{\circ} \mathrm{C}$, não houve diferença na duração (STa, ${ }^{\circ} \mathrm{C}$ dia) do ciclo total e dos subperíodos da melancia entre os três métodos de soma térmica utilizados para a mesma data de semeadura. Não ocorreram diferenças na duração (STa, ${ }^{\circ} \mathrm{C}$ dia) do ciclo total e dos subperíodos semeadura-emergência (SEEM), emergência-florescimento (EM-FL) e florescimento-colheita (FL-CO) da melancia entre os três métodos de soma térmica utilizados para a mesma data de semeadura. A duração em soma térmica dos subperíodo EM-FL é similar nas duas datas de semeadura, entretanto, nos subperíodos SE-EM e FL$\mathrm{CO}$, ocorrem diferenças consideradas elevadas entre épocas.

\section{AGRADECIMENTOS}

Ao Conselho Nacional de Desenvolvimento Científico e Tecnológico (CNPq), pelo auxílio financeiro para N.A. Streck e G.A. Buriol (Bolsa de Produtividade em Pesquisa). Aos revisores Ad Hoc pelas valiosas sugestões e comentários em versões anteriores do manuscrito.

\section{REFERÊNCIAS}

ALVES, V.C. et al. Exigências térmicas do arroz irrigado "IAC 4440”. Revista Brasileira de Agrometeorologia, v.8, n.2, p.171-174, 2000
ARNOLD, C.Y. Maximum-minimum temperatures as a basis for computing heat units. Journal of the American Society for Horticultural Sciences, v.76, p.682-692, 1960.

BAKER, J.T.; REDDY, V.R. Temperature effects on phenological development and yield of muskmelon. Annals of Botany, v.87, n.5, p.605-613, 2001.

BARBANO, M.T. et. al. Temperatura-base e acúmulo térmico no subperíodo semeadura-florescimento masculino em cultivares de milho no Estado de São Paulo. Revista Brasileira de Agrometeorologia, v. 9, n.2, p.261-268, 2001.

BONHOMME, R. Bases and limits to using 'degree day' units. European Journal of Agronomy, v.13, n.1, p.1-10, 2000.

BRUNINI, O. et al. Temperatura base para alface "White Boston”, em um sistema de unidades térmicas. Bragantia, v.85, n.19, p.214-219, 1976.

EMBRAPA. Sistema Brasileiro de Classificação de Solos. Local: Embrapa-SPI: Embrapa-CNPS, 2006. 306p.

GILMORE JUNIOR., E.C.; ROGERS, J.S. Heat units as a method of measuring maturity in corn. Agronomy Journal, v.50, n.10, p.611-615, 1958.

GRANIER, C.; TARDIEU, F. Is thermal time adequate for expressing the effects of temperature on sunflower leaf development? Plant, Cell and Environment, v.21, n.7, p.695-703, 1998.

IBGE, Produção Agrícola Municipal SCP/DEPLAN. Capturado em 7 abr 2008. Online. Disponível na Internet: http://www.sidra.ibge.gov.br/

JEFFERIES, R.A.; MACKERRON, D.K.L. Thermal time as a non-destructive method of estimating tuber initiation in potatoes. Journal of Agricultural Science, v.108, p.249252, 1987

LORENZ O.A.; MAYNARD D.N. Knott's handbook for vegetable growers. 3.ed. Wiley, 1988. 456 p.

McMASTER, G.S.; WILHELM, W.W. Growing degree-days: one equation, two interpretations. Agricultural and Forest Meteorology, v.87, p.291-300, 1997.

MORENO, J.A. Clima do Rio Grande do Sul. Porto Alegre: Secretaria da Agricultura, 1961. 46p.

PAULA, F.L.M. et al. Soma térmica de algumas fases do ciclo de desenvolvimento da batata (Solanum tuberosum L.). Ciência Rural, v.35, n.5, p.1034-1042, 2005.

SANGOI, L.; SILVA, P.R.F. Comparação entre métodos de cálculo de unidades térmicas e os dias do calendário na previsão de subperíodos de desenvolvimento do girassol. Pesquisa Agropecuária Brasileira, v.21, p. 901-908, 1986. 
SEDGLEY M; BUTTROSE, M.S. Some effects of light intensity, daylength and temperature on fowering and pollen tube growth in the watermelon. Annals of Botany, v.42, p.609-616, 1978.

STRECK, N.A. et al. Improving predictions of developmental stages in winter wheat: a modified Wang and Engel model. Agricultural and Florest Meteorology, v.115, p.139-150, 2003.

STRECK, N.A. et al. Estimativa do plastocrono em meloeiro (Cucumis melo L.) cultivado em estufa plástica em diferentes épocas do ano. Ciência Rural, v.35, n.6, p.1275-1280, 2005.
WUTKE, E.B. et al. Estimativa de temperatura base e grausdia para feijoeiro nas diferentes fases fenológicas. Revista Brasileira de Agrometeorologia, v.8, n.1, p.55-61, 2000.

XUE, Q. et al. Predicting leaf appearance in field grown winter wheat: evaluating linear and non-linear models. Ecological Modelling, v.175, p.261-270, 2004.

YIN, X. et al. A nonlinear model for crop development as a function of temperature. Agricultural and Florest Meteorology, v.7, p.1-16, 1995. 